\title{
A região dos desejos e das aventuras: diálogos sobre grandes projetos de integração e desenvolvimento na Amazônia nos séculos XIX e XX*
}

The region of desires and adventures: dialogues on major projects of integration and development in the Amazon in the nineteenth and twentieth centuries

César Martins de Souza ${ }^{\star *}$

Palavras-chave:

Amazônia

Grandes projetos

Desenvolvimento

Resumo: Desde o período colonial a região amazônica se constituiu em um desafio aos conquistadores e aventureiros que muitas vezes desapareciam ou morriam na floresta, em sua busca de novas riquezas. Ao final do século XIX, sobretudo ao longo do XX, a Amazônia se tornou em base de projetos que visavam o progresso do Brasil a partir da exploração das riquezas da região. Neste sentido, um mergulho na literatura e nos debates da historiografia permite refletir sobre o processo que levou a região amazônica ao centro da cena nacional em políticas e projetos de integração e desenvolvimento, transformando a região em produtor de matéria-prima para o capitalismo nacional e mundial, o que provocou fortes impactos socioambientais.

Keywords:

Amazonia

Great projects

Development

Abstract: Since the colonial period the Amazonia region was a challenge to settlers and adventurers that used to either disappear or die in the forest, in their search for wealth. At the end of the 19th century, and mainly throughout the 20th, Amazonia became the basis for projects that sought to reach Brazilian progress through the exploitation of the region's natural wealth. In this manner, an in-depth study in the literature and in debates from historiography allows us to reflect about the process that took the Amazonia region into the national center stage regarding integration and development projects and policies. All this resulted in the transformation of the region into a raw material producer for national and global capitalism, causing serious socio-environmental impacts.

Recebido em 3 de novembro de 2017. Aprovado em 27 de dezembro de 2017.

\section{Um sentido para a História da} Amazônia?

Uma das atividades curriculares básicas e fundamentais dos cursos de graduação em História é Teoria da História, na qual o não iniciado adentra o universo da historiografia e é levado a compreender teorias que embasam a disciplina e ao mesmo tempo indagam sobre o possível sentido para História. O sentido da História é um tema abordado por diversos teóricos da disciplina ao se indagarem sobre uma possível direção nos caminhos temporais trilhados pelas sociedades humanas.
Klein discute como Kant pensava o progresso da história humana, como sendo a história do desenvolvimento da liberdade (KLEIN, 2013). Para Kanaan, Fukuyama acreditava que uma série de eventosatéaQuedado Muro deBerlim encaminharam o fim da História, não da vida e da morte no planeta, mas dos conflitos e desenvolvimentos, porque sem a divisão que marcou a Guerra Fria, passaria a haver estabilidade no mundo desenvolvido. Nos países subdesenvolvidos, a democracia não se afirmaria em um primeiro momento, ficando a cargo dos países desenvolvidos, como afirma Kanaan, em um artigo sobre Fukuyama:

\footnotetext{
* O presente artigo foi desenvolvido a partir dos estudos e diálogos realizados durante atividades de Investigador Visitante no Instituto de Ciências Sociais/Universidade de Lisboa e de projetos de pesquisa desenvolvidos na Universidade federal do Pará (UFPA), sob a coordenação do autor. ${ }^{*}$ Doutor em História pela Universidade Federal Fluminense, Mestre em Antropologia pela UFPA, Licenciado e Bacharel em História pela UFPA Professor Adjunto da Universidade Federal do Pará (UFPA), desenvolvendo atividades docentes no Campus de Altamira e no Programa de PósGraduação em Linguagens e Saberes da Amazônia. E-mail: <cesar@ufpa.br>.
} 
A democracia apenas seria possível para os países desenvolvidos economicamente com um processo de industrialização já consolidado. Os demais países, pobres e 'atrasados', estariam vulneráveis aos regimes totalitários, ao socialismo, ou ainda, aos regimes democráticos dependentes dos países desenvolvidos.

O 'fim da História', último estágio de avanço econômico, não significaria o fim da história social ou fim dos acontecimentos naturais como vida ou morte, mas sim, uma sociedade tecnológica que pudesse suprir todas as necessidades humanas. Atingindo este estágio, ocorreria o fim do desenvolvimento dos princípios e das instituições básicas, pois todas as questões realmente importantes estariam resolvidas.

Não haveria precedente para os níveis de desenvolvimento proporcionados, tanto para os países industrializados quanto para os países pobres. Estes últimos receberiam uma série de investimentos sociais visando uma igualdade de oportunidades a todos os cidadãos do mundo. (KANAAN, 2005, p.1-2).

Os estudos de Klein e Kanaan problematizam como Kant e Fukuyama acreditavam que a História avança rumo ao desenvolvimento, garantindo uma vida melhor para a humanidade. $\mathrm{O}$ que vem a ser desenvolvimento? A crença no processo de industrialização como motor do desenvolvimento provocou, no fim do século XIX, visões otimistas de que a humanidade caminhava para um período de paz e estabilidade, na virada do século XIX para o XX (HOBSBAWM, 2008).

A crença no desenvolvimento baseado na industrialização, sob o comando das grandes potências, que promoveria então a melhoria da humanidade é um tema que marca os séculos XIX e XX. Thomas (2010) analisa como, desde a industrialização do século XVIII, se tornou forte na Inglaterra a ideia de que países desenvolvidos promoveriam a industrialização e a partir dela o aprimoramento da humanidade. Desta forma, valores ético-morais, como o respeito à natureza e a relação mais próxima dos humanos com o meio ambiente teriam se consolidado no século XIX, baseados em uma releitura de tradições religiosas e na busca pelo aprimoramento das pessoas e das sociedades.

$\mathrm{Na}$ virada do século XIX para o XX, portanto, o desenvolvimento está relacionado com a paz e a relação mais próxima dos humanos com o meio ambiente e no XX em investimentos sociais, tecnologias universais e igualdade de situações aos cidadãos de todo o globo. Para além dos discursos sobre a aproximação dos humanos com o meio ambiente ou em investimentos sociais para a superação da desigualdade, desde o século XIX a Amazônia passou a ser vista como palco de grandes projetos que ignoram suas populações, visando apenas fornecer matéria-prima para as grandes indústrias.

Mesmo entre pessoas nascidas na região amazônica, como o Barão de Santa Anna Nery, vigora, desde o século XIX a visão de que a floresta amazônica deve ser analisada como uma região com grande potencial para proporcionar lucros ao capital internacional:

Já começa a faltar madeira na velha Europa, despojada de suas florestas pré-históricas; não está longe o tempo em que seremos forçados a buscar no Novo Mundo novas reservas florestais. A Amazônia conserva em depósito, para séculos, uma reserva de madeira capaz de alimentar todas as indústrias locais e estrangeiras. Há tesouros que dormem e esperam a passagem dos corajosos pioneiros: estamos certos que estes não se farão esperar por muito tempo. O homem sempre se dirige para onde haja dinheiro para ganhar e força de trabalho para ser utilizada. (NERY, 1979, p. 78).

Esta forma de conceber a região como um território a ser desbravado e ocupado em busca de riquezas, contradiz a ideia de que a História, no fim do XIX e também no fim do XX, caminhava para um período de melhoria da condição humana e de respeito às naturezas não humanas. A tese sobre a caminhada da História rumo ao aperfeiçoamento das sociedades humanas entra em contradição com a condição imposta à Amazônia e parece confirmar as visões de Euclides da Cunha (2006), que pensa a região como "fora" do tempo histórico. 
Apenas enxergando a Amazônia como fora do tempo histórico torna-se possível conceber que os países desenvolvidos estejam conduzindo o mundo a condições melhores enquanto usam a Amazônia para garantir este "desenvolvimento", ignorando sua fauna e flora $e$ as sociedades humanas. O lugar da região amazônica na História da humanidade é um tema importante porque permite refletir sobre como diversos países e mesmo aqueles que possuem a região dentro de seus territórios, veem e se posicionam sobre a região. As obras literárias também se constituem em uma fonte importante sobre o assunto, pois a partir delas se pode problematizar olhares sobre diferentes momentos da História da Amazônia. Esta reflexão permite analisar como a ideia de desenvolvimento da humanidade surge como ideologia que impõe valores, se apropria das riquezas da região e provoca impactos ambientais grandes e, em muitos casos, definitivos para a imensa floresta tropical.

O escritor paraense Dalcídio Jurandir (1997) em Chove nos campos de Cachoeira, publicado originalmenteem 1940, retrata em diversas passagens a natureza amazônica, o movimento dos rios, o tempo da chuva, os campos alagados, as frutas, os animais e os seres humanos construindo suas vidas entrelaçados à natureza. $\mathrm{O}$ tempo narrativo parece correr mais lentamente porque tenta seguir a lógica da natureza, sem que o narrador interrompa para pensar em formas de fazer progredir as pequenas cidades ou colocar uma visão utilitarista da floresta. A prosa de Jurandir, ao colocar o tempo da natureza em primeiro plano, segue um caminho contrário ao dos grandes empreendimentos implementados na região, porque pensa a partir da natureza amazônica e não sobre ela.

Ao longo dos séculos, as árvores centenárias, os rios e os animais se constituem em desafio a escritores, viajantes naturalistas, ensaístas, políticos e grandes capitalistas. Muitas vezes, os rios gigantescos, árvores de até cinquenta metros de altura, diversificada fauna e flora foram vistos como obstáculos ao desenvolvimento e em outros momentos como o epicentro do desejo do grande capital. Ao mesmo tempo em que a floresta movimentou a imaginação, muitos aventureiros se embrenharam nas matas amazônicas em busca de alcançar lugares fantásticos relatados por missionários e viajantes.

Inferno, paraíso, lugar de monstros ou de criaturas celestiais. A floresta amazônica vista como um enclave, uma espécie de entrave ao progresso do país, por muitos ensaístas, veio a ser, no século XIX, vista como um espaço a ser explorado para garantia de desenvolvimento. Como se lhe coubesse um lugar especial no capitalismo mundial, como fornecedor de matéria-prima, eletricidade e laboratório ao ar livre para as biotecnologias, a região amazônica deixou de ser o paraíso perdido para se constituir em um espaço que alimenta desejos ao redor do globo.

Em todas as minhas atividades de pesquisa, desde que ainda era estudante de graduação, tenho desenvolvido pesquisas sobre ciclos econômicos e grandes projetos de integração e desenvolvimento que tiveram a região amazônica como foco e eixo central. Assim, desenvolvi pesquisas sobre A borracha na Amazônia, a construção da Rodovia Transamazônica e da Hidrelétrica de Belo Monte, além de ter estudado diversos outros trabalhos e conhecido in loco projetos hidrelétricos, rodoviários, minerais e agropecuários implementados em diferentes lugares da região, o que me leva a problematizar os impactos socioambientais da exploração das riquezas amazônicas pelo grande capital internacional, bem como os prejuízos permanentes experimentados pelas populações locais, sobretudo em relação a transformação profunda em seus modos de vida e a desagregação de suas bases socioeconômicas.

No presente artigo, busco, portanto, fazer uma reflexão sobre o lugar que a Amazônia ocupa na História do planeta, sobretudo diante do grande capital internacional. Para construir o texto, mergulho em minha própria trajetória como pesquisador, dialogando com a teoria sobre grandes projetos, a historiografia e com as obras literárias sobre os diferentes momentos da História, em que a Amazônia foi transformada em objeto e foco de debates que visavam explorar as riquezas da região e inseri-la na rota dos grandes centros econômicos do mundo. 


\section{Do “uso" da Amazônia aos impactos socioambientais}

Em meados do século XIX, a tranquilidade de diversas populações amazônicas sofreu profundas transformações com a descoberta em 1840 do processo de vulcanização, por Goodyer e posteriores incorporações da borracha no rol de uma das matérias-primas fundamentais para a crescente industrialização no mundo. $A$ árvore que chora, como definiu Gondim (2007), foi tema de muitas obras literárias consagradas no Brasil e no mundo, como também de dezenas de pesquisas e ensaios acadêmicos. A economia da borracha se constituiu em um dos temas mais importantes da História da Amazônia, de forma que é muito presente na historiografia e em obras literárias sobre a região. Em 1880, o conhecido escritor francês de ficção científica, Júlio Verne, publicou uma obra ambientada na Amazônia, na qual expressa um otimismo com as possibilidades de desenvolvimento para Manaus:

O comércio de Manaus deve aumentar sensivelmente com a escala dos vapores. Efetivamente, as madeiras de construção ou de marcenaria, o cacau, a borracha, o café, a salsaparrilha, a canade-açúcar, o anil, a noz moscada, o peixe salgado, a manteiga de tartaruga, todos esses diversos artigos encontram ali numerosos cursos de água para os transportar: o rio Negro para norte e oeste, o Madeira para o sul e oeste, o Amazonas, finalmente, para leste, até o litoral do Atlântico. A situação desta cidade é, portanto, magnífica, e deve contribuir poderosamente para sua prosperidade. (VERNE, 1966, p.148).

A prosperidade com a exploração das chamadas drogas do sertão e com os animais e madeira, animavam o narrador de A jangada, que prevê um ciclo de prosperidade para Manaus. O ciclo chegou logo após a publicação da obra, pois as principais cidades amazônicas cresceram rapidamente e viram suas economias sofrerem grande movimentação, a partir da extração de borracha. A borracha provocou transformações profundas nas duas maiores cidades da Amazônia, Belém e Manaus, que experimentaram o fausto de ver surgir grandes teatros no interior da floresta, Teatro da Paz e Teatro Amazonas, possibilitou a abertura de largas avenidas, a importação de roupas da Europa, pelos barões da cidade e o surgimento de palacetes e residências suntuosos (DIAS, 2007).

Outras cidades amazônicas também prosperaram na segunda metade do século XIX, como Óbidos e Porto Velho, palco da ferrovia Madeira-Mamoré, bem como novas cresceram e/ou surgiram, como Altamira, Parintins, Rio Branco, entre tantas outras. Vapores chegavam com frequência do Rio de Janeiro, trazendo novidades. Óperas partiam da Europa para se apresentar em Belém e Manaus, a imprensa divulgava os suntuosos bailes promovidos pela burguesia que vivia na euforia de um cotidiano marcado por valores parisienses. Em Belém, uma loja de tecidos até hoje existente denominada Paris n'América traduz em seu nome e em sua estrutura o fausto do período.

Manaus, Belém e outras cidades possuem diversos monumentos à memória do tempo em que as riquezas da borracha conduziram a Amazônia ao fausto da belle époque (SARGES, 2002). Enquanto as riquezas faziam prosperar estas cidades, havia uma sociedade que cada vez mais era expulsa para as periferias, onde pudesse ficar invisível aos olhares de visitantes e das elites.

Belém e Manaus abriam grandes avenidas e praças, em um processo de amplo reordenamento urbano, mas provocavam a expulsão das pessoas mais pobres para lugares afastados e escondidos. Se a economia da borracha é baseada no extrativismo que, quando comparado aos futuros ciclos econômicos da região, provoca menos impactos ambientais, os impactos sociais são grandes, como a exclusão social urbana ou a forma de trabalho conhecida como aviamento, que escravizava migrantes nordestinos e até mesmo ribeirinhos e indígenas ao fazê-los devedores permanentes dos barracões dos seringais. Este processo de escravidão por dívidas ficou consagrado na literatura universal, sob a pena do escritor português Ferreira Castro, na obra $O$ seringal: 
Dum dia para o outro, o seringueiro de 'saldo', que suportara uma dezena de anos na selva, em luta com a natureza implacável, para adquirir os dinheiros necessários ao regresso, via-se sem nada - e sem saber até como o haviam despojado. De novo pobre, com a família e a terra, preocupação constante do seu exílio, a atraírem-no de longe, ele sufocava uma vez mais, as saudades, a dor do tempo perdido, e regressava ao seringal, tão miserável como a primeira hora em que lá aportara. (CASTRO, 1956, p. 39).

A escravidão levava os seringueiros a uma vida degradada e espoliada de seus direitos básicos, como narrado na obra de Castro. Enquanto as indústrias mundiais prosperavam com a economia da borracha (SANTOS, 1980), as pessoas eram escravizadas no interior da floresta, por um sistema opressor e desumanizador. Ao analisar a obra de Castro, Menezes Neto (2011) afirma que este sistema provocou visões negativas sobre a floresta, percebida por seringueiros como um inimigo despótico que tudo fazia para expulsar os humanos e manipulá-los como se fossem títeres.

Diante dos problemas na exploração da borracha, o alvo das críticas foca na floresta amazônica ao invés dos coronéis da borracha que enriqueciam em Belém, Manaus e a partir deles em várias partes do mundo. A economia da borracha abriu e expandiu cidades na Amazônia, aumentou a ocupação humana e iniciou um período de ciclos econômicos, projetos desenvolvimentistas e impactos ambientais. A pergunta não apenas sobre este período quanto em relação aos projetos desenvolvimentistas do século XX é: quais as melhorias vivenciadas pelas populações amazônicas com a exploração da borracha? A economia gomífera trouxe em seu bojo ainda novos desdobramentos, sob a forma de grandes obras de impacto implementadas na região, visando explorar o látex, transportar as riquezas amazônicas e integrar esta região.

A construção da ferrovia Madeira-Mamoré é um momento que explicita uma visão sobre a região como um lugar de passagem. A rodovia passa pela Amazônia, mas não foi pensada para a
Amazônia e nem pela Amazônia. Não apenas índios e ribeirinhos foram atingidos pelo empreendimento, como também os operários que tiveram dificuldades em lidar com a floresta.

A floresta também apareceu na construção da Madeira-Mamoré como uma grande inimiga das atividades econômicas humanas e dos grandes projetos de integração, como se agisse com vontade própria para expulsar os operários. As doenças vitimaram números elevados de operários $\mathrm{e}$ ainda provocaram impactos durante a construção (HARDMAN, 2005). Quando as árvores caíam para abrir clareiras ao empreendimento, era como se o grande capital obtivesse vitória contra a natureza até então indomável. O escritor amazonense Márcio Souza, em Mad Maria, descortina o universo cotidiano da ferrovia em uma obra que ficou conhecida na literatura nacional. Ao narrar os problemas na construção da ferrovia, aponta que os engenheiros consideravam que a natureza precisava ser vencida, pois agia por "uma espécie de transe não premeditado e sua fúria ascendia rapidamente até a destruição" (SOUZA, 2005, p.106).

A ferrovia marcou o início de um século desenvolvimentista para a região amazônica, entretanto, naquele momento as memórias sobre o empreendimento ressaltam a vitória da floresta contra os "invasores". Os milhares de trabalhadores mortos em conflitos ou por doenças, destacam, de forma dramática, que novos grandes projetos de integração da Amazônia ou exploração de suas riquezas enfrentariam a marca da derrota para a natureza.

Os resultados negativos da construção da Madeira-Mamoré não levaram em consideração os indicadores sobre agressões às populações tradicionais da região e à natureza. A floresta supostamente venceu, mas assistiu a chegada de uma enxurrada de operários, engenheiros e aventureiros, movidos pelo desejo de estabelecer um grande empreendimento de integração, uma ferrovia, o que provocou impactos ao longo do século XX. Ao mesmo tempo, o narrador de Mad Maria considerava que o empreendedor e engenheiro da ferrovia, o estadunidense Farquhar: 
Tinha a maior veneração pela instituição do lucro e chegava a acreditar que o lucro era a maior criação de Deus. $\mathrm{Na}$ natureza tudo era fonte de lucro e ele tinha certeza que um Deus esperto não teria agido assim por nada. (SOUZA, 2005, p. 91).

Polanyi argumenta que o avanço da ação do grande capital no mundo transformou o significado da natureza e do trabalho humanos em mercadoria fictícia. Em meados do século XIX, segundo o autor, ocorreu uma grande transformação que permitiu ao capital industrial transformar o globo terrestre em mercado consumidor, mão de obra e matériaprima. Desta forma, "o homem, sob o nome de mão de obra, e a natureza, sob o nome de terra, foram colocados à venda" (POLANYI, 2012, p. 146). A dessacralização da natureza e dos seres humanos iniciou um longo período ainda vigente em que a transformação da natureza em mercadoria é mais importante do que os impactos negativos que as ações sobre ela possam proporcionar ao planeta.

A narrativa de Souza destaca que ferrovia Madeira-Mamoré terminou "ligando nada com lugar nenhum". A afirmação em Mad-Maria se encontra com a visão de Polanyi que expressava uma crítica ao fato de a natureza e os seres humanos haverem sido transformados em mercadoria fictícia. A natureza vista como fonte de lucro ao capital internacional, colocou cada vez mais a região amazônica no centro da cena e deixou vulnerável a existência da gigantesca floresta tropical.

NaconstruçãodeFordlândia, permaneceram os debates sobre a necessidade de vencer a floresta, $\mathrm{o}$ mesmo ocorrendo na construção de rodovias como Belém-Brasília, Perimetral Norte e Transamazônica. Da mesma forma foram desenhados também, nos século XX e XXI, a construção de hidrelétricas enfocando a necessidade da vitória sobre a selva e provocando danos irreparáveis ao meio ambiente e às vidas das pessoas que vivem no entorno das áreas alagados, como ocorreu na construção da Hidrelétrica de Tucuruí, no Pará (MAGALHÃES, 1994).

Em seu estudo sobre Fordlândia, Grandin (2010) conclui que o industrial estadunidense Henry Ford enxergava o Brasil e principalmente a Amazônia, com um olhar colonizador. A região do rio Tapajós, onde a Ford Company instalou uma cidade, plantação de seringueiras e fábrica de exploração de látex seria, segundo a lógica de Henry Ford, libertada pela chegada do progresso. A lógica utilizada ignora natureza e as práticas culturais de populações locais, para colocar a indústria de borracha como algo necessário para a Amazônia, por promover o progresso.

A floresta, conforme descrita em A selva (CASTRO, 1956), escravizava e diminuía as capacidades dos seres humanos, por isso deveria ser confrontada pela massiva chegada de migrantes e de projetos para integrar e desenvolver a região. A dominação da floresta sobre os humanos está no centro da preocupação com os impactos que poderiam ser provocados pelos novos grandes empreendimentos em curso na segunda metade do século XX. Um pouco antes, durante a Segunda Guerra Mundial, para abastecer os aliados nos combates de guerra, foram enviadas centenas de homens à selva amazônica, objetivando extrair borracha. As memórias dos "soldados da borracha", como ficaram conhecidos os seringueiros deste período, relatam um elevado número de mortes, devido às doenças, insetos e animais selvagens (CAMPOS, 2006), o que reforça o argumento de que a natureza é inimiga do progresso.

Drummond, em seu estudo sobre a indústria de extração de manganês na Serra do Navio, no Amapá, considera que as atividades de mineração desenvolvidas pelo capital transnacional no Amapá, geraram, em consequência, mais impactos ambientais que sociais, remodelando espacialmente a região em que foi instalada (DRUMMOND, 2000). No mesmo sentido, Carvalho (1994), ao analisar a Industrialização tardia e grandes projetos na Amazônia, problematiza os impactos causados por diversos empreendimentos econômicos e conclui que pecuária, garimpo e mineração, além dos problemas sociais que ocasionam aos lugares onde ocorrem, provocam impactos ambientais de amplo alcance e por um longo período.

Comovimos, um processo histórico iniciado na virada do século XIX para o XX, deu início a uma série de ciclos econômicos de exploração dos recursos da Amazônia que foi transformada em 
mercadoria para o grande capital internacional. Entretanto, durante o boom da economia da borracha e nos demais projetos implementados, a região amazônica não se torna em foco de uma reestruturação social, tampouco se percebe uma preocupação com a garantia da manutenção de seu patrimônio biológico, cada vez mais presente em debates sobre a garantia da qualidade de vida no planeta.

Na segunda metade do século XX ocorreu a intensificação de projetos de exploração mineral, como a já referida neste texto, indústria de manganês no Amapá, ou a extração diversificada de minerais no Sul e Sudeste do Pará. Com o crescimento da produção mineral e indústria madeireira, cresceu a necessidade de integrar a Amazônia ao restante do país, a partir de pontes, ferrovias e rodovias, visando a exportação dos minerais, produtos agropecuários e madeira. Nesse contexto, no governo de Juscelino Kubistchek foi construída a rodovia BelémBrasília que provocou impactos ambientais, com o crescimento de cidades às suas margens $\mathrm{e}$ também a expulsão de populações tradicionais que viviam no trajeto da estrada, devido a ação de grandes empresas, frente à valorização das terras (HEBETTE; MARIN, 1977).

Dando prosseguimento a agenda das obras de integração, durante a ditadura foram construídas diversas rodovias, para assinalar a nova cartografia desenvolvimentista que se estabelecia na Amazônia, na qual se destaca, como a mais propagandeada e mais extensa, a rodovia Transamazônica. Martins de Souza (2015) afirma que, quando se construiu a rodovia Transamazônica, na década de 1970, vários escritores, ensaístas e articulistas temiam que a intervenção na floresta pudesse provocar impactos à saúde pública. As memórias da ferrovia MadeiraMamoré foram evocadas com frequência como uma referência dos riscos de a Transamazônica vir a se tornar cenário para propagação de epidemias, pelo fato de os operários e colonos que migraram para os projetos oficiais de agricultura ao longo da rodovia não conhecerem a floresta.

O mesmo fenômeno ocorrera em outros momentos, como na exploração da borracha durante a Segunda Guerra Mundial, quando os trabalhadores, em sua maioria naturais do nordeste do Brasil, não sabiam lidar com a selva, o que os tornou mais expostos aos ataques de animais e às dificuldades com a natureza.

O migrante isolado, enfrentando a natureza, é um tema recorrente nos relatos sobre o cotidiano dos grandes projetos e faz parte de um discurso que retira da natureza sua condição como fundamental a existência da vida no globo terrestre, para colocá-la na condição de obstáculo ao progresso. O progresso e desenvolvimento são um tema recorrente em trabalhos de articulistas, ensaístas e escritores sobre a Amazônia. O físico Albert Einstein em uma obra sobre suas principais ideias, Como vejo o mundo, demonstra uma visão pessimista sobre o progresso e a exploração das riquezas:

Todas as riquezas do mundo, ainda mesmo nas mãos de um homem inteiramente devotado à ideia do progresso jamais trarão o menor desenvolvimento moral para a humanidade. Somente seres humanos excepcionais e irrepreensíveis suscitam ideias generosas e ações elevadas. Mas o dinheiro polui tudo e degrada sem piedade a pessoa humana. (EINSTEIN, 1997, p. 13-14).

A busca pelas riquezas amazônicas, defendida por Nery (1979), na virada do século XIX para o XX, transformou a Amazônia em uma grande mercadoria para o capital transnacional. A mercadoria fictícia, como argumenta Polanyi (2012), é uma forma de buscar dominar humanos e o meio ambiente, atribuindo-lhes valor de uso.

Goodland e Irwin, ao comentarem frentes agropecuárias e grandes projetos implementados na Amazônia, pela ditadura, expressam a preocupação de que em breve a floresta viesse sofrer danos definitivos:

O desflorestamento e a agricultura em vasta escala planejados como parte integral e resultado direto da implantação do sistema rodoviário da Amazônia irão, sem dúvida, causar maiores danos ao ambiente do que as próprias estradas. 
(...) Quando, porém, é rompido o equilíbrio ecológico nem sempre é possível restabelecê-lo, já que algumas alterações são irreversíveis. (GOODLAND; IRWIN, 1975, p. 45).

Os autores expressam a preocupação com os rumos do desenvolvimentismo brasileiro e os riscos ambientais. A construção de estradas como a Transamazônica e a Belém-Brasília foi planejada como parte de projetos agropecuários para ocupar e desenvolver a Amazônia, os quais, para os autores, geram impactos muito maiores do que a própria construção das rodovias. Em todo o livro provocam os leitores a pensar nos impactos definitivos que se poderia estar provocando naquele momento, com empreendimentos na gigantesca floresta tropical que cada vez mais são desenhados e instalados na região amazônica.

\section{A região do futuro?}

Na década de 1970, a região foi colocada no centro da cartografia desenvolvimentista, como o eixo de uma série de projetos que possibilitariam alçar o Brasil à condição de potência mundial. Rodovias, hidrelétricas e projetos de extrativismo mineral foram implementados na segunda metade do século XX e apontavam a concretização dos sonhos de ensaístas e escritores, mas também como argumentam Goodland e Irwin, um risco ao equilíbrio ecológico da região e do planeta:

Não obstante as florestas amazônicas estão sendo rapidamente destruídas e suas terras submetidas à exploração irracional para obtenção de lucros em curto prazo, o que acabará por se transformar, com igual rapidez, em desastrosos problemas futuros. (1975, p. 63).

Os lucros na exploração da Amazônia foram pensados em curto prazo, como na extração de borracha, na exploração mineral e na construção de grandes obras de impacto e integração. Apesar de ser retratada constantemente em veículos de comunicação como relacionada ao futuro da vida no planeta, a região amazônica encontra no passado e no presente a explicação para as dificuldades em efetivamente viabilizar a sobrevivência de populações locais, bem como dos animais e da flora. Após o encerramento de cada novo empreendimento, como vimos ao longo deste texto, fica como saldo uma série de problemas e poucos benefícios para a região.

A intervenção na floresta, inserida no contexto internacional como algo que pode ser explorado e consumido pelo grande capital, não pensa em benefícios para a própria região. Quando alguma vantagem surge, ocorre como efeito colateral da exploração de riquezas e não como a razão do empreendimento, porque estes, desde o século XIX, visam garantir infraestrutura e matéria-prima para o grande capital, podendo vir, contudo, a gerar impactos socioambientais irreparáveis a Amazônia e ao globo terrestre.

\section{Referências}

CAMPOS, André Luiz Vieira de. Políticas internacionais de saúde na Era Vargas: o Serviço Especial de Saúde Pública, 1942-1960. Rio de Janeiro: Fiocruz, 2006.

CARVALHO, David Ferreira. Industrialização tardia e grandes projetos. In: D’INCAO, Maria Ângela; SILVEIRA, Isolda Maciel (Orgs.). A Amazônia e a crise da modernização. Belém: Museu Paraense Emílio Goeldi, 1994. p. 427-446.

CASTRO, Ferreira de. A selva. Lisboa: Guimarães Editores, 1956.

CUNHA, Euclides da. A margem da História. São Paulo: Martin Claret, 2006.

DIAS, Edinéia Mascarenhas. A ilusão do fausto: Manaus,1890-1920. Manaus: Valer, 2007.

DRUMMOND, Investimentos privados, impactos ambientais e qualidade de vida num empreendimento mineral amazônico: o caso da mina de manganês de Serra do Navio (Amapá). História, Ciências, Saúde, Rio de Janeiro, v. 6 (suplemento), p. 753-792, set. 2000. 
EINSTEIN, Albert. Como vejo o mundo. São Paulo: Círculo do Livro, 1997.

FUKUYAMA, F. O fim da História e o último homem. Rio de Janeiro: Rocco, 1992.

GONDIM, Neide. A invenção de Amazônia. Manaus: Valer, 2007.

GOODLAND, Robert; IRWIN, Howard. A selva amazônica: do inferno verde ao deserto vermelho. São Paulo: Itatiaia/USP, 1975.

GRANDIN, Greg. Fordlândia: ascensão e queda da cidade esquecida de Henry Ford na selva. Rio de Janeiro: Rocco, 2010.

HARDMAN, Francisco Foot. Trem fantasma: a ferrovia Madeira-Mamoré e a modernidade na selva. São Paulo: Companhia das Letras, 2005.

HEBETTE, Jean; MARIN, Rosa Acevedo. Saúde e colonização. In: HEBETTE, Jean et al. Colonização, desenvolvimento e modelos econômicos. Belém: NAEA/UFPA, 1977. p. 7-43.

HOBSBAWM, Eric. Era dos extremos: o breve século XX (1914-1991). São Paulo: Companhia das Letras, 2008.

JURANDIR, Dalcídio. Chove nos campos de Cachoeira. Belém: CEJUP, 1997.

KANAAN, Hanen Sarkis. O fim da História e o último homem (Francis Fukuyama). Percursos, Florianópolis, v. 6, n. 1, p. 1-10, 2005. Disponível em: $\quad<$ http://www.revistas.udesc.br/index.php/ percursos/article/view/1451/1224>. Acesso em: 27 out. 2017.

KLEIN, Joel Thiago. Kant sobre o progresso na História. Ética. Florianópolis, v. 12, n. 1, p. 67100, jun. 2013. Disponível em: <https://periodicos. ufsc.br/index.php/ethic/article/viewFile/1677- 2954.2013v12n1p67/25273>. Acesso em: 27 out. 2017.

MAGALHÃES, Sônia Barbosa. As grandes hidrelétricas e as populações camponesas. In: D'INCAO, Maria Ângela; SILVEIRA, Isolda Maciel (Orgs.). A Amazônia e a crise da modernização. Belém: Museu Paraense Emílio Goeldi, 1994. p. 447-456.

MARTINS DE SOUZA, César. Morte, saúde e ditadura na construção da Transamazônica. Tempos históricos. Cascavel-PR, v. 19, p. 65-91, $2^{\circ}$ sem. 2015.

MENEZES Neto, Geraldo M. História ambiental e literatura: o seringal nas obras de Ferreira de Castro e Firmino Teixeira do Amaral. Tempos históricos, Cascavel-PR, v. 15, p. 155-178, $2^{\circ}$ sem. 2011.

NERY, Barão de Santa Anna. O país das amazonas. São Paulo: Itatiaia/USP, 1979.

POLANYI, Karl. A grande transformação: as origens de nossa época. Rio de Janeiro: Elsevier, 2012.

SANTOS, Roberto. História econômica da Amazônia (1800-1920). São Paulo: T. A. Queiroz, 1980.

SARGES, Maria de Nazaré. Belém: riquezas produzindo a belle-époque (1870-1912). Belém: Pakatatu, 2002.

SOUZA, Márcio. Mad Maria. Rio de Janeiro: Record, 2005.

THOMAS, Keith. O homem e o mundo natural: mudanças de atitude em relação às plantas e aos animais (1500-1800). São Paulo: Companhia das Letras, 2010. 